\title{
Utilización de bioinsumos, su relación con la micorrización espontánea en el cultivo de Avena negra (Avena strigosa)
}

Correa, Amilcar; Cossoli* , Marcela R.; Romero, Amalia, M. E.; Barrionuevo, Cristian M.; Iglesias, María C.

Cát. de Microbiología Agrícola. FCA - UNNE. Sargento Cabral 2131 - CP 3400, Corrientes. Tel. /fax:+54(379) 4427589 int. 158

*E-mail: mcossoli@gmail.com

Área temática: Bioinsumos

Introducción: Las rizobacterias son capaces de estimular el crecimiento de las plantas por una variedad de mecanismos que incluyen la fijación del nitrógeno atmosférico, producción y liberación de hormonas promotoras del crecimiento radical, aumentando la solubilidad de algunos otros nutrientes, como $\mathrm{P}$, estas actividades generan un aumento de la producción de exudados promoviendo el crecimiento de otros organismos rizosféricos, entre ellos, los hongos micorrícicos nativos.Teniendo en cuenta una producción agrícola sutentable y considerando la extracción de nutrientes por parte de los cultivos, el polvo de roca es utilizado como fuente en la remineralización de suelos pobres o lixiviados y su utilización será más efectiva cuando se realice de forma conjunta con prácticas culturales que estimulen la microbiota del suelo.El objetivo del trabajo fue evaluar la utilización de diferentes inoculantes y el agregado de polvo de basalto y su relación con la micorrización espontánea, en el cultivo de Avena negra.

Materiales y métodos: El ensayo se estableció en un lote implantado con Avena negra (Avena strigosa) perteneciente a la Escuela Regional Agropecuaria, Ganadería e Industrias Afines (ERAGIA-UNNE), en la ciudad de Corrientes. La densidad de siembra del cultivo era de $87 \mathrm{~kg} . \mathrm{ha}^{-1}$. Se trabajó con 8 tratamientos que surgieron de la combinación de tres biofertilizantes mas un tratamiento de referencia y la utilización de polvo de basalto (dosis: $5 \mathrm{tn} \cdot \mathrm{ha}^{-1}$ ), quedando los tratamientos diferenciados de la siguiente forma: Testigo con Basalto y Testigo sin Basalto, Bradyrhizobium japonicum $\left(1.10^{9}\right.$ UFC.ml $^{-1} ; 155 \mathrm{ml}^{-1} \mathrm{a}^{-}$ ${ }^{1}$ ) con Basalto y sin Basalto, Pseudomonas fluorescens ( $1.10^{9}$ UFC. $^{-1}$; $620 \mathrm{ml} \cdot \mathrm{ha}^{-1}$ ) con Basalto y sin Basalto y un aislamiento fijador de Nitrógeno A3 $\left(1,87.10^{7}\right.$ UFC.ml $^{-1}$; $1,21$. ha $\left.^{-1}\right)$ con Basalto y sin Basalto. Los tratamientos fueron aplicados a los 24 días de la siembra, en parcelas de $4 \mathrm{~m}^{2}$. Para la evaluación de la micorrización espontánea, se realizaron 2 muestreos. El $1^{\text {o }}$ fue a los 56 días de la aplicación de los tratamientos, luego hubo un pastoreo y se realizó el $2^{\circ}$ muestreo a los 22 días posteriores a este. En ambos muestreos se extrajeron raíces de las plantas de avena que fueron lavadas y teñidas con Azul de tripán, para la observación de la infección micorrícica, pudiendo determinar el \% de micorrización y la observación de las diferentes estructuras fúngicas existentes. Los datos fueron analizados mediante prueba $\mathrm{T}$ para muestras independientes $(p \leq 0,05)$.

Resultados: En el $1^{\circ}$ Muestreo, el \% de micorrización varió entre 72 y $85 \%$. En los tratamientos con A3 se observó una diferencia estadísticamente significativa a favor de la aplicación de basalto, entre los demás tratamientos no se observaron diferencias. En el $2^{\circ}$ Muestreo, hubo una mayor variación entre los tratamientos en la micorrización, siendo esta entre 64 y $98 \%$, aquí se encontraron diferencias significativas a favor de la aplicación de basalto en el tratamiento Testigo y en el inoculado con Pseudomonas $f$, en cambio en el caso de los tratamientos inoculados con A3, hubo mayor micorrización en el que no tenía Basalto.

Con respecto a las estructuras fúngicas, en relación a la presencia de arbúsculos, en el $1^{\circ}$ muestreo fueron más parejos los tratamientos, con una tendencia a aumentar en aquellos que tenían Basalto pero la situación fue inversa para los que tenían Bradyrhizobium j, en cambio, en el segundo muestreo, hubo mayor fluctuación entre tratamientosexistiendo la misma tendencia en los que tenían basalto pero en este caso La situación no fue así en los inoculados con A3. Con respecto a presencia de vesículas, en el $1^{\circ}$ muestreo se encontró mayor número en los tratamientos inoculados con Pseudomonas y A3 mientras que en el segundo muestreo prácticamente no se visualizaron estas enstructuras. Con respecto al $\mathrm{N}^{\circ}$ de campos donde solo se visualizaban hifas, estos fueron mayores en el segundo muestreo en la mayoría de los tratamientos.

Conclusiones: Hubo una tendencia de mayor micorrización en el $2^{\circ}$ muestreo, luego del rebrote, pero con menor presencia de estructuras funcionales del hongo. Se pudo observar una respuesta diferencial de la micorrización a la utilización de los diferentes bioinsumos empleados en esta experiencia.

Agradecimientos: Escuela Regional Agropecuaria, Ganadería e Industrias Afines (ERAGIA-UNNE). 